\title{
Per-oral Endoscopic Myotomy (POEM) for Esophagogastric Junction Outflow Obstruction (EGJOO): A Multicenter Pilot Study
}

Chelsea C. Jacobs DO ${ }^{1}$, Yaseen Perbtani DO ${ }^{2}$, Dennis Yang MD², Mohammad A. Al-Haddad $\mathrm{MD}^{3}$, Ite Obaitan MBBS, MPH${ }^{3}$, Mohamed Othman $\mathrm{MD}^{4}$, Shawn Groth MD ${ }^{5}$, Amrita Sethi $\mathrm{MD}^{6}$, Emil Agarunov ${ }^{6}$, Alessandro Repici $\mathrm{MD}^{7}$, Roberta Maselli MD, $\mathrm{PhD}^{7}$, Alessia Galtieri $\mathrm{MD}^{7}$, Jacob Moremen ${ }^{8}$, Haley N. Jenkins ${ }^{8}$, Jason B. Samarasena MD ${ }^{9}$, Kenneth J. Chang MD ${ }^{9}$, Peter V. Draganov $\mathrm{MD}^{2}$

${ }^{1}$ Department of Internal Medicine, University of Florida, Gainesville, FL, USA

${ }^{2}$ Division of Gastroenterology and Hepatology, University of Florida, Gainesville, FL, USA

${ }^{3}$ Division of Gastroenterology and Hepatology, Indiana University, Indianapolis, IN, USA

${ }^{4}$ Section of Gastroenterology and Hepatology, Baylor College of Medicine, Houston, TX, USA

${ }^{5}$ Division of General Thoracic Surgery, Baylor College of Medicine, Houston, TX, USA

${ }^{6}$ Division of Digestive and Liver Diseases, Columbia University, New York, NY, USA

${ }^{7}$ Division of Gastroenterology, Humanitas Research Hospital, Milan, Italy

${ }^{8}$ Department of Surgery, University of Mississippi Medical Center, Jackson, MI, USA

${ }^{9}$ Division of Gastroenterology and Hepatology, University of California Irvine, Irvine, CA, USA

COI Disclosure: PV Draganov is a consultant for Boston Scientific, Cook Medical, MicroTech, and Olympus. D. Yang is a consultant for Boston Scientific, Lumendi, and US Endoscopy. M Al-Haddad is a speaker for Boston Scientific. M Othman is a consultant for Olympus, Boston Scientific, Lumendi, Apollo, Con Med, and Abbvie. S Groth is a speaker for Intuitive Surgical Inc. A Sethi is a consultant for Boston Scientific, Olympus, and Fujifilm. A Repici is a consultant, speaker, and on the advisory board for Erbe, Fujifilm, and Medtronic, and a consultant and advisory board for Boston Scientific. R Maselli is a consultant and speaker for ERBE. J Samarasena is a consultant and speaker for Medtronic, Olympus, Mauna Kea, Conmed, a consultant for Steris and Microtech, and an owner of Docbot. KJ Chang is a consultant for Olympus, ERBE, Medtronic, EndoGastric Solutions, and Apollo. CC Jacobs, Y Perbtani, E Agarunov, A Galtieri, I Obaitan, J Moremen, and HN Jenkins, have no conflicts of interest, disclosure, or financial relationships relevant to this publication.

\section{Correspondence:}

Peter V Draganov MD

Professor of Medicine

1329 SW 16th Street, Room \# 5251

Gainesville, FL 32608

USA

Tel: $+1(352)$ 273-9474

Fax: +1 (352) 627-9002

This is the author's manuscript of the article published in final edited form as:

Jacobs, C. C., Perbtani, Y., Yang, D., Al-Haddad, M. A., Obaitan, I., Othman, M., Groth, S., Sethi, A., Agarunov, E., Repici, A., Maselli, R., Galtieri, A., Moremen, J., Jenkins, H. N., Samarasena, J. B., Chang, K. J., \& Draganov, P. V. (2020). Per-Oral Endoscopic Myotomy for Esophagogastric Junction Outflow Obstruction: A Multicenter Pilot Study. 


\section{INTRODUCTION}

Esophagogastric junction outflow obstruction (EGJOO) is a rare but increasingly recognized diagnosis as described by The Chicago Classification of Esophageal Motility Disorders version $3.0(\mathrm{CC} v 3.0)^{1}$. On high-resolution manometry (HRM), EGJOO is characterized by elevated integrated relaxation pressure (IRP) of the lower esophageal sphincter (LES), yet with some preserved esophageal peristalsis ${ }^{2-4}$. Little consensus exists on the preferred therapeutic approach $^{3}$. Although conceptually POEM should address the measurable dysfunction in the LES, few data exist to support this ${ }^{5}$. Thus, we aimed to evaluate the safety and efficacy of POEM for the treatment of symptomatic EGJOO.

\section{METHODS}

This is a multicenter retrospective analysis of patients with symptomatic EGJOO who underwent POEM between Feb-2014 and Feb-2020. Institutional Review Board approval was obtained at each institution (6 U.S., 1 from Italy). POEM was performed as previously described ${ }^{5}$. All patients underwent pre-POEM HRM and upper endoscopy. Technical and clinical success defined as completion of the POEM and post-POEM Eckardt score $\leq 3$ without additional interventions, respectively. Adverse events were graded based on the ASGE lexicon ${ }^{6}$.

\section{RESULTS}

Fifty-five patients underwent POEM for EGJOO (Table 1). Mean duration of symptoms prior to POEM was 70.1 months. Nearly half of patients $(45.5 \%)$ had failed prior treatment. The mean baseline Eckardt score and IRP were $7.1 \pm 2.64$ and $25.34 \pm 26.25 \mathrm{mmHg}$, respectively. Functional lumen imaging probe (FLIP) was abnormal in $88.2 \%$ of patients. Barium retention on esophagram was seen in $95.6 \%$. 
Technical success was achieved in all patients (100\%) with mean procedure time of $73.2 \pm 35.6$ minutes (Table 1). Clinical success was attained in $47 / 55$ patients (94\%) at median follow-up of 117 days. There were 2 minor (mucosal perforation), 2 mild (pneumoperitoneum requiring decompression) and 1 severe adverse event (1 mucosal perforation treated with esophageal stent with full recovery). Mean post-POEM IRP $(\mathrm{n}=17)$ was $8.88 \pm 7.03 \mathrm{mmHg}$, a mean difference of 10.64 (95\% CI 5.82-15.46; p=0.0003) from pre-POEM HRM. Post-POEM pH monitoring $(n=18)$ was abnormal in $66 \%$. Twenty-five patients had post-POEM endoscopy and esophagitis was seen in 10/25 (grade A 4/25, grade B 6/25, grade C or D 0/25) (Table 1 ).

\section{DISCUSSION}

Given that EGJOO defining measurable characteristic is failure of LES to relax symptomatic improvement after POEM is expected. Indeed, our preliminary data support POEM as an effective and safe therapy ${ }^{4}$. Our findings expand on earlier report in which POEM was effective for a variety of non-achalasia motility disorders, including EGJOO ${ }^{5}$. Noteworthy, since POEM is an invasive procedure that permanently disrupts the LES, accurate pre-procedure diagnosis with exclusion of secondary causes of mechanical obstruction is essential. Furthermore, it is important to highlight the dynamic nature of symptoms in EGJOO, as spontaneous resolution has been previously documented ${ }^{3}$. In our study, the duration of symptoms pre-POEM averaged 70 months with $45.5 \%$ of patients undergoing prior therapy making spontaneous resolution unlikely. As such, POEM should only be considered in patients with persistent symptoms, as those described in this study. Abnormal EndoFLIP results may identify EGJOO patients that would have high success with the current treatments used in achalasia, including $\mathrm{POEM}^{7}$. Thus, incorporating EndoFLIP data and stratifying patients based on symptoms into future prospective EGJOO studies is recommended ${ }^{7}$. Similarly, there is accumulating data identifying an association 
between opioids and LES mechanics, with many patients exhibiting EGJOO patterns on HRM when opioids were received within 24 hours ${ }^{1,8}$. As this is investigated further, we suggest the discontinuation of all opioids $>24$ hours prior to HRM during evaluation for POEM.

Our study is not without limitations. At this point in time, there is very limited data on the utility of POEM in EGJOO, thus this study serves as a proof-of-concept. There was no standardized pre- and post-procedure management, thus post-POEM testing was done at the discretion of the performing physician. Subsequently, the observed occurrence of post-POEM GERD may be inaccurately high due to selection bias but there is no reason to believe the frequency of postPOEM GERD to be different for EGJOO than for achalasia.

Nevertheless, we present the largest series to date which serves both as an aid in clinical decision-making and as a springboard for future higher quality studies. Furthermore, our multicenter data provide external validity to our findings. We did not have opioid-use data available, highlighting the necessity of this endpoint in future studies. Despite our relatively short follow-up period, it is reasonable to expect these findings to be similar to that of POEM for achalasia where we have well documented mid- and long-term results. Our findings support the possible role of POEM as safe and effective in everyday practice but also the need for further larger prospective studies. 
Table 1. Patient and procedure characteristics $(n=55)$

\begin{tabular}{|c|c|c|}
\hline & Pre-POEM & Post-POEM \\
\hline Age (years), mean \pm SD & $58.8 \pm 16.09$ & \\
\hline Female, $\mathrm{n}=(\%)$ & $33(60)$ & \\
\hline Male, $\mathrm{n}=(\%)$ & $22(40)$ & \\
\hline $\begin{array}{l}\text { Duration of symptoms (months), mean } \pm \\
\text { SD }\end{array}$ & $70.1 \pm 100.03$ & \\
\hline Prior therapy, no. (\%) & $25(45.5)$ & \\
\hline Pharmacotherapy, total $\mathrm{n}=(\%)$ & $10(18.0)$ & $2(3.6)$ \\
\hline Botulinum toxin injections, total $n=(\%)$ & $15(27.0)$ & $0(0.0)$ \\
\hline Pneumatic dilation, total $\mathrm{n}=(\%)$ & $12(22.0)$ & $1(1.8)$ \\
\hline Surgical myotomy, $\mathrm{n}=(\%)$ & $0(0.0)$ & $1(1.8)$ \\
\hline $\begin{array}{l}\text { Pharmacotherapy and botulinum toxin } \\
\text { injection, } n=(\%)\end{array}$ & $7(13.0)$ & $0(0.0)$ \\
\hline $\begin{array}{l}\text { Pharmacotherapy, botulinum toxin } \\
\text { injection, and pneumatic dilation, } \mathrm{n}=(\%)\end{array}$ & $3(5.0)$ & $0(0.0)$ \\
\hline $\begin{array}{l}\text { Botulinum toxin injections and } \\
\text { pneumatic dilation, } \mathrm{n}=(\%)\end{array}$ & $1(1.8)$ & $0(0.0)$ \\
\hline Esophagitis on endoscopy, $\mathrm{n} / \mathrm{N}=(\%)$ & $\begin{array}{l}\text { Grade A 2/55 (2.0) } \\
\text { Grade B 0/55 (0.0) } \\
\text { Grade C 0/55 (0.0) } \\
\text { Grade D 0/55 (0.0) }\end{array}$ & $\begin{array}{l}\text { Grade A 4/25 (16.0) } \\
\text { Grade B 6/25 (24.0) } \\
\text { Grade C 0/25 (0) } \\
\text { Grade D 0/25 (0) }\end{array}$ \\
\hline IRP $(\mathrm{mmHg})$, mean $\pm \mathrm{SD}$ & $25.34 \pm 26.25$ & $8.88 \pm 7.03$ \\
\hline $\begin{array}{l}\text { Difference from pre- to post-POEM IRP } \\
(\mathrm{mmHg}), \text { mean }(95 \% \mathrm{CI} \text {; p-value) }\end{array}$ & & $\begin{array}{l}10.64 \\
(5.82-15.46,0.0003)\end{array}$ \\
\hline 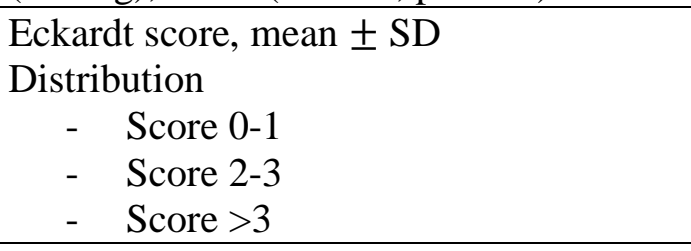 & $\begin{array}{l}7.1 \pm 2.64 \\
4 \% \\
3 \% \\
90 \% \\
\end{array}$ & $\begin{array}{l}1.22 \pm 1.50 \\
64 \% \\
30 \% \\
6 \% \\
\end{array}$ \\
\hline $\begin{array}{l}\text { Abnormal EndoFLIP (EGJ-DI } \leq 2.8 \\
\mathrm{~mm} 2 / \mathrm{mmHg}), \mathrm{n} / \mathrm{N}=(\%)\end{array}$ & $15 / 17(88.2)$ & \\
\hline $\begin{aligned} & \text { Barium Esophagram } \\
&- \text { Retention of liquids } \mathrm{n} / \mathrm{N}=(\%) \\
&- \text { Retention of tablet } \mathrm{n} / \mathrm{N}=(\%)\end{aligned}$ & $\begin{array}{l}21 / 46(45.6) \\
12 / 25(48.0)\end{array}$ & \\
\hline \multicolumn{3}{|l|}{ Procedural characteristics } \\
\hline Procedural time (minutes), mean \pm SD & & $73.2 \pm 35.6$ \\
\hline Anterior/Posterior approach, $\mathrm{n}(\%)$ & & $28(50.9) / 27(49.0)$ \\
\hline Total myotomy length $(\mathrm{cm})$, mean $\pm \mathrm{SD}$ & & $12.58 \pm 3.33$ \\
\hline \multicolumn{3}{|l|}{ Post-procedural results } \\
\hline Technical success, n (\%) & & $55(100)$ \\
\hline Successful clinical response, $\mathrm{n}(\%)$ & & $47(94.0)$ \\
\hline Adverse events, $\mathrm{n}$ & & $\begin{array}{l}\text { Minor: } 2 / 55 \\
\text { Mild: } 2 / 55 \\
\text { Severe: } 1 / 55\end{array}$ \\
\hline
\end{tabular}




\begin{tabular}{|l|l|l|}
\hline Adverse events, $\mathrm{n}(\%)$ & $5(9.6)$ \\
\hline Revision of POEM, $\mathrm{n}(\%)$ & & $1(1.8)$ \\
\hline $\begin{array}{l}\text { Abnormal time } \mathrm{pH}>4 \text { on 24-hour } \mathrm{pH} \\
\text { monitoring, } \mathrm{n} / \mathrm{N}(\%)\end{array}$ & $12 / 18(66.6)$ \\
\hline $\begin{array}{l}\text { Duration of follow-up (days), median } \\
\text { (IQR) }\end{array}$ & & $117(48-281)$ \\
\hline
\end{tabular}

\section{REFERENCES}

1. $\quad$ Beveridge C, et al. Gastroenterol Hepatology. 2020;16(3):131-138.

2. Kahrilas PJ, et al. Neurogastroenterol Motility. 2015;27(2):160-174.

3. Pérez-Fernández MT, et al. Neurogastroenterol Motility. 2016;28(1):116-126.

4. Ihara E, et al. Digestion. 2017;95(1):29-35.

5. Khashab MA, et al. Endosc International Open. 2018;6(8):E1031.

6. Cotton PB, et al. Gastrointest Endoscopy. 2010;71(3):446-454.

7. Triggs JR, et al. Clinical Gastroenterology and Hepatology. November 2019.

8. Ratuapli SK, et al. American Journal of Gastroenterology. 2015;110(7):979-984. 


\section{Per-oral Endoscopic Myotomy (POEM) for Esophagogastric Junction Outflow Obstruction (EGJOO): A Multicenter Pilot Study}

Chelsea C. Jacobs DO ${ }^{1}$, Yaseen Perbtani DO ${ }^{2}$, Dennis Yang MD², Mohammad A. Al-Haddad $\mathrm{MD}^{3}$, Ite Obaitan MBBS, MPH${ }^{3}$, Mohamed Othman $\mathrm{MD}^{4}$, Shawn Groth MD ${ }^{5}$, Amrita Sethi $\mathrm{MD}^{6}$, Emil Agarunov ${ }^{6}$, Alessandro Repici $\mathrm{MD}^{7}$, Roberta Maselli MD, $\mathrm{PhD}^{7}$, Alessia Galtieri $\mathrm{MD}^{7}$, Jacob Moremen ${ }^{8}$, Haley N. Jenkins ${ }^{8}$, Jason B. Samarasena MD ${ }^{9}$, Kenneth J. Chang MD ${ }^{9}$, Peter V. Draganov $\mathrm{MD}^{2}$

${ }^{1}$ Department of Internal Medicine, University of Florida, Gainesville, FL, USA

${ }^{2}$ Division of Gastroenterology and Hepatology, University of Florida, Gainesville, FL, USA

${ }^{3}$ Division of Gastroenterology and Hepatology, Indiana University, Indianapolis, IN, USA

${ }^{4}$ Section of Gastroenterology and Hepatology, Baylor College of Medicine, Houston, TX, USA

${ }^{5}$ Division of General Thoracic Surgery, Baylor College of Medicine, Houston, TX, USA

${ }^{6}$ Division of Digestive and Liver Diseases, Columbia University, New York, NY, USA

${ }^{7}$ Division of Gastroenterology, Humanitas Research Hospital, Milan, Italy

${ }^{8}$ Department of Surgery, University of Mississippi Medical Center, Jackson, MI, USA

${ }^{9}$ Division of Gastroenterology and Hepatology, University of California Irvine, Irvine, CA, USA

COI Disclosure: PV Draganov is a consultant for Boston Scientific, Cook Medical, MicroTech, and Olympus. D. Yang is a consultant for Boston Scientific, Lumendi, and US Endoscopy. M Al-Haddad is a speaker for Boston Scientific. M Othman is a consultant for Olympus, Boston Scientific, Lumendi, Apollo, Con Med, and Abbvie. S Groth is a speaker for Intuitive Surgical Inc. A Sethi is a consultant for Boston Scientific, Olympus, and Fujifilm. A Repici is a consultant, speaker, and on the advisory board for Erbe, Fujifilm, and Medtronic, and a consultant and advisory board for Boston Scientific. R Maselli is a consultant and speaker for ERBE. J Samarasena is a consultant and speaker for Medtronic, Olympus, Mauna Kea, Conmed, a consultant for Steris and Microtech, and an owner of Docbot. KJ Chang is a consultant for Olympus, ERBE, Medtronic, EndoGastric Solutions, and Apollo. CC Jacobs, Y Perbtani, E Agarunov, A Galtieri, I Obaitan, J Moremen, and HN Jenkins, have no conflicts of interest, disclosure, or financial relationships relevant to this publication.

\section{Correspondence:}

Peter V Draganov MD

Professor of Medicine

1329 SW 16th Street, Room \# 5251

Gainesville, FL 32608

USA

Tel: +1 (352) 273-9474

Fax: +1 (352) 627-9002 


\section{INTRODUCTION}

Esophagogastric junction outflow obstruction (EGJOO) is a rare but increasingly recognized diagnosis as described by The Chicago Classification of Esophageal Motility Disorders version $3.0(\mathrm{CC} v 3.0)^{1}$. On high-resolution manometry (HRM), EGJOO is characterized by elevated integrated relaxation pressure (IRP) of the lower esophageal sphincter (LES), yet with some preserved esophageal peristalsis ${ }^{2-4}$. Little consensus exists on the preferred therapeutic approach $^{3}$. Although conceptually POEM should address the measurable dysfunction in the LES, few data exist to support this ${ }^{5}$. Thus, we aimed to evaluate the safety and efficacy of POEM for the treatment of symptomatic EGJOO.

\section{METHODS}

This is a multicenter retrospective analysis of patients with symptomatic EGJOO who underwent POEM between Feb-2014 and Feb-2020. Institutional Review Board approval was obtained at each institution (6 U.S., 1 from Italy). POEM was performed as previously described ${ }^{5}$. All patients underwent pre-POEM HRM and upper endoscopy. Technical and clinical success defined as completion of the POEM and post-POEM Eckardt score $\leq 3$ without additional interventions, respectively. Adverse events were graded based on the ASGE lexicon ${ }^{6}$.

\section{RESULTS}

Fifty-five patients underwent POEM for EGJOO (Table 1). Mean duration of symptoms prior to POEM was 70.1 months. Nearly half of patients $(45.5 \%)$ had failed prior treatment. The mean baseline Eckardt score and IRP were $7.1 \pm 2.64$ and $25.34 \pm 26.25 \mathrm{mmHg}$, respectively. Functional lumen imaging probe (FLIP) was abnormal in $88.2 \%$ of patients. Barium retention on esophagram was seen in $95.6 \%$. 
Technical success was achieved in all patients (100\%) with mean procedure time of $73.2 \pm 35.6$ minutes (Table 1). Clinical success was attained in $47 / 55$ patients (94\%) at median follow-up of 117 days. There were 2 minor (mucosal perforation), 2 mild (pneumoperitoneum requiring decompression) and 1 severe adverse event (1 mucosal perforation treated with esophageal stent with full recovery). Mean post-POEM IRP $(\mathrm{n}=17)$ was $8.88 \pm 7.03 \mathrm{mmHg}$, a mean difference of 10.64 (95\% CI 5.82-15.46; p=0.0003) from pre-POEM HRM. Post-POEM pH monitoring $(n=18)$ was abnormal in $66 \%$. Twenty-five patients had post-POEM endoscopy and esophagitis was seen in 10/25 (grade A 4/25, grade B 6/25, grade C or D 0/25) (Table 1 ).

\section{DISCUSSION}

Given that EGJOO defining measurable characteristic is failure of LES to relax symptomatic improvement after POEM is expected. Indeed, our preliminary data support POEM as an effective and safe therapy ${ }^{4}$. Our findings expand on earlier report in which POEM was effective for a variety of non-achalasia motility disorders, including EGJOO ${ }^{5}$. Noteworthy, since POEM is an invasive procedure that permanently disrupts the LES, accurate pre-procedure diagnosis with exclusion of secondary causes of mechanical obstruction is essential. Furthermore, it is important to highlight the dynamic nature of symptoms in EGJOO, as spontaneous resolution has been previously documented ${ }^{3}$. In our study, the duration of symptoms pre-POEM averaged 70 months with $45.5 \%$ of patients undergoing prior therapy making spontaneous resolution unlikely. As such, POEM should only be considered in patients with persistent symptoms, as those described in this study. Abnormal EndoFLIP results may identify EGJOO patients that would have high success with the current treatments used in achalasia, including $\mathrm{POEM}^{7}$. Thus, incorporating EndoFLIP data and stratifying patients based on symptoms into future prospective EGJOO studies is recommended ${ }^{7}$. Similarly, there is accumulating data identifying an association 
between opioids and LES mechanics, with many patients exhibiting EGJOO patterns on HRM when opioids were received within 24 hours ${ }^{1,8}$. As this is investigated further, we suggest the discontinuation of all opioids $>24$ hours prior to HRM during evaluation for POEM.

Our study is not without limitations. At this point in time, there is very limited data on the utility of POEM in EGJOO, thus this study serves as a proof-of-concept. There was no standardized pre- and post-procedure management, thus post-POEM testing was done at the discretion of the performing physician. Subsequently, the observed occurrence of post-POEM GERD may be inaccurately high due to selection bias but there is no reason to believe the frequency of postPOEM GERD to be different for EGJOO than for achalasia.

Nevertheless, we present the largest series to date which serves both as an aid in clinical decision-making and as a springboard for future higher quality studies. Furthermore, our multicenter data provide external validity to our findings. We did not have opioid-use data available, highlighting the necessity of this endpoint in future studies. Despite our relatively short follow-up period, it is reasonable to expect these findings to be similar to that of POEM for achalasia where we have well documented mid- and long-term results. Our findings support the possible role of POEM as safe and effective in everyday practice but also the need for further larger prospective studies. 
Table 1. Patient and procedure characteristics $(n=55)$

\begin{tabular}{|c|c|c|}
\hline & Pre-POEM & Post-POEM \\
\hline Age (years), mean \pm SD & $58.8 \pm 16.09$ & \\
\hline Female, $\mathrm{n}=(\%)$ & $33(60)$ & \\
\hline Male, $\mathrm{n}=(\%)$ & $22(40)$ & \\
\hline $\begin{array}{l}\text { Duration of symptoms (months), mean } \pm \\
\text { SD }\end{array}$ & $70.1 \pm 100.03$ & \\
\hline Prior therapy, no. (\%) & $25(45.5)$ & \\
\hline Pharmacotherapy, total $\mathrm{n}=(\%)$ & $10(18.0)$ & $2(3.6)$ \\
\hline Botulinum toxin injections, total $n=(\%)$ & $15(27.0)$ & $0(0.0)$ \\
\hline Pneumatic dilation, total $\mathrm{n}=(\%)$ & $12(22.0)$ & $1(1.8)$ \\
\hline Surgical myotomy, $\mathrm{n}=(\%)$ & $0(0.0)$ & $1(1.8)$ \\
\hline $\begin{array}{l}\text { Pharmacotherapy and botulinum toxin } \\
\text { injection, } n=(\%)\end{array}$ & $7(13.0)$ & $0(0.0)$ \\
\hline $\begin{array}{l}\text { Pharmacotherapy, botulinum toxin } \\
\text { injection, and pneumatic dilation, } \mathrm{n}=(\%)\end{array}$ & $3(5.0)$ & $0(0.0)$ \\
\hline $\begin{array}{l}\text { Botulinum toxin injections and } \\
\text { pneumatic dilation, } \mathrm{n}=(\%)\end{array}$ & $1(1.8)$ & $0(0.0)$ \\
\hline Esophagitis on endoscopy, $\mathrm{n} / \mathrm{N}=(\%)$ & $\begin{array}{l}\text { Grade A 2/55 (2.0) } \\
\text { Grade B 0/55 (0.0) } \\
\text { Grade C 0/55 (0.0) } \\
\text { Grade D 0/55 (0.0) }\end{array}$ & $\begin{array}{l}\text { Grade A 4/25 (16.0) } \\
\text { Grade B 6/25 (24.0) } \\
\text { Grade C 0/25 (0) } \\
\text { Grade D 0/25 (0) }\end{array}$ \\
\hline IRP $(\mathrm{mmHg})$, mean $\pm \mathrm{SD}$ & $25.34 \pm 26.25$ & $8.88 \pm 7.03$ \\
\hline $\begin{array}{l}\text { Difference from pre- to post-POEM IRP } \\
(\mathrm{mmHg}), \text { mean }(95 \% \mathrm{CI} \text {; p-value) }\end{array}$ & & $\begin{array}{l}10.64 \\
(5.82-15.46,0.0003)\end{array}$ \\
\hline 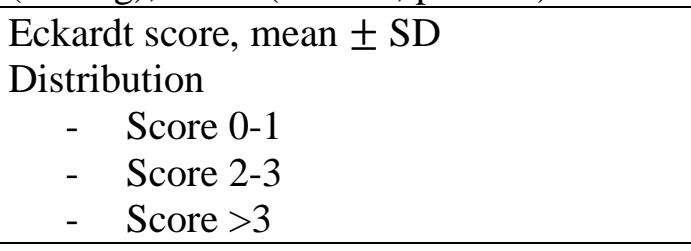 & $\begin{array}{l}7.1 \pm 2.64 \\
4 \% \\
3 \% \\
90 \% \\
\end{array}$ & $\begin{array}{l}1.22 \pm 1.50 \\
64 \% \\
30 \% \\
6 \% \\
\end{array}$ \\
\hline $\begin{array}{l}\text { Abnormal EndoFLIP (EGJ-DI } \leq 2.8 \\
\mathrm{~mm} 2 / \mathrm{mmHg}), \mathrm{n} / \mathrm{N}=(\%)\end{array}$ & $15 / 17(88.2)$ & \\
\hline $\begin{aligned} & \text { Barium Esophagram } \\
&- \text { Retention of liquids } \mathrm{n} / \mathrm{N}=(\%) \\
&- \text { Retention of tablet } \mathrm{n} / \mathrm{N}=(\%)\end{aligned}$ & $\begin{array}{l}21 / 46(45.6) \\
12 / 25(48.0)\end{array}$ & \\
\hline \multicolumn{3}{|l|}{ Procedural characteristics } \\
\hline Procedural time (minutes), mean \pm SD & & $73.2 \pm 35.6$ \\
\hline Anterior/Posterior approach, $\mathrm{n}(\%)$ & & $28(50.9) / 27(49.0)$ \\
\hline Total myotomy length $(\mathrm{cm})$, mean $\pm \mathrm{SD}$ & & $12.58 \pm 3.33$ \\
\hline \multicolumn{3}{|l|}{ Post-procedural results } \\
\hline Technical success, n (\%) & & $55(100)$ \\
\hline Successful clinical response, $\mathrm{n}(\%)$ & & $47(94.0)$ \\
\hline Adverse events, $\mathrm{n}$ & & $\begin{array}{l}\text { Minor: } 2 / 55 \\
\text { Mild: } 2 / 55 \\
\text { Severe: } 1 / 55\end{array}$ \\
\hline
\end{tabular}




\begin{tabular}{|l|l|l|}
\hline Adverse events, $\mathrm{n}(\%)$ & $5(9.6)$ \\
\hline Revision of POEM, $\mathrm{n}(\%)$ & & $1(1.8)$ \\
\hline $\begin{array}{l}\text { Abnormal time } \mathrm{pH}>4 \text { on 24-hour } \mathrm{pH} \\
\text { monitoring, } \mathrm{n} / \mathrm{N}(\%)\end{array}$ & $12 / 18(66.6)$ \\
\hline $\begin{array}{l}\text { Duration of follow-up (days), median } \\
\text { (IQR) }\end{array}$ & & $117(48-281)$ \\
\hline
\end{tabular}

\section{REFERENCES}

1. $\quad$ Beveridge C, et al. Gastroenterol Hepatology. 2020;16(3):131-138.

2. Kahrilas PJ, et al. Neurogastroenterol Motility. 2015;27(2):160-174.

3. Pérez-Fernández MT, et al. Neurogastroenterol Motility. 2016;28(1):116-126.

4. Ihara E, et al. Digestion. 2017;95(1):29-35.

5. Khashab MA, et al. Endosc International Open. 2018;6(8):E1031.

6. Cotton PB, et al. Gastrointest Endoscopy. 2010;71(3):446-454.

7. Triggs JR, et al. Clinical Gastroenterology and Hepatology. November 2019.

8. Ratuapli SK, et al. American Journal of Gastroenterology. 2015;110(7):979-984. 